\title{
研究短解文
}

\section{宫崎喺土呂久産ダンフリリ石及び朝鮮遂安金山 第洞産ルードウキグ石の化學成分に就きて}

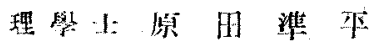

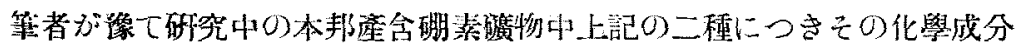

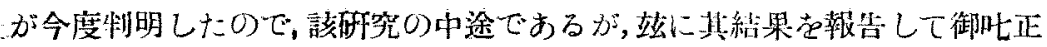

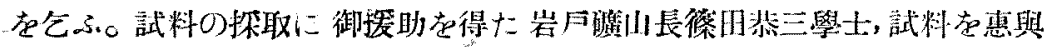

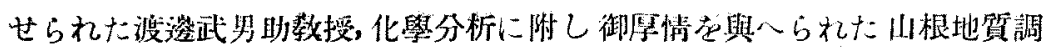

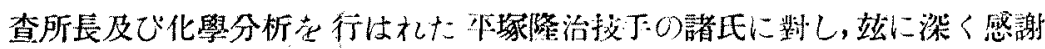
し, 敬意竟す。

\section{1 土昷久産ダンプリ石}

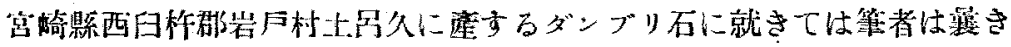

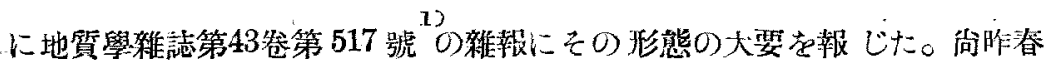
四月京都帝大に於ける日本地質學會總會に於て今迄に利明した同硣物の性

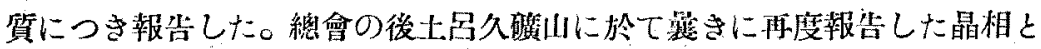

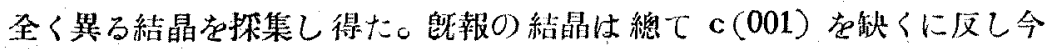

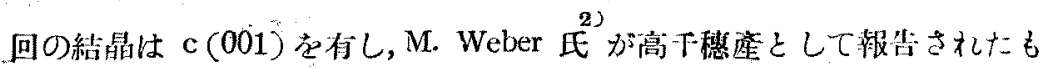
のに其晶相は殆んどー致する。

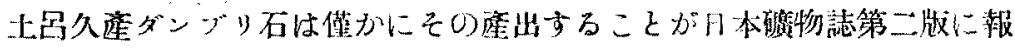

1) 地留學祕誌，43，(1986).

2) Z. X. 37, 620 621, (1903). 
ぜられてみるのみで何籍詳しく研究されてるなかつたのである。

M. Weber 氏が䯩干穂座ダンブリ石として其呼究堂發表された當時本邦 に於ては高䅹にダンブリ石が產出するこをは弘く知られてるなかつた。 從つて尾本と混同したのであらうとかと、或はそれは宫崎縣西田杵郡山裹

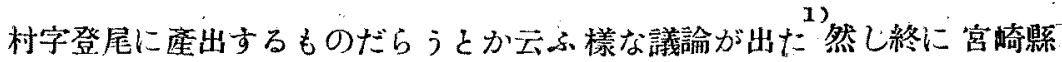
西曰杵郡岩戸村土号久にダンブリ石が多量に產したと云ふコとが制明した

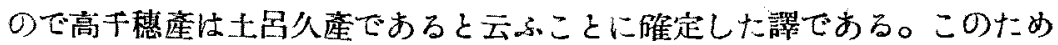
に從來尾本產と云はれてるた結晶の中にも上号久座が混在してるるだらう

第壹 表

\begin{tabular}{|c|c|c|}
\hline I & II & III \\
\hline Wt\% & Wt\% & Mol\% \\
\hline $\mathrm{SiO}_{2} \quad \cdots \cdots 48.22$ & $\ldots \ldots \ldots \ldots 48.29$ & $\ldots .8040, \quad 2.00$ \\
\hline $\mathrm{B}_{2} \overline{\mathrm{O}}_{3} \ldots \ldots 28.56$ & $\ldots \ldots \ldots \ldots 28.61$ & $\ldots . .4108$ \\
\hline $\mathrm{Al}_{2} \mathrm{O}_{3} \ldots \ldots, \quad 0.22$ & .......... 0.22 & $\ldots \ldots 0.0022\} 1.02$ \\
\hline $\mathrm{Fe}_{2} \mathrm{O}_{3}, \ldots \ldots, 0.44$ & $\ldots \ldots \ldots, 0,44$ & $\cdots \cdots 0.0028)$ \\
\hline $\begin{array}{llll}M g O & \ldots \ldots & 0.11\end{array}$ & $\ldots \ldots \ldots \ldots, 0.1 t$ & $\ldots 0.0027]_{1}$ \\
\hline .....22.29 & $\ldots \ldots \ldots \ldots 22.33$ & $\ldots \ldots 0.3982\}^{1.00}$ \\
\hline $\begin{array}{lllll}H_{2} & O & \ldots . . & 0.32\end{array}$ & …........ & \\
\hline 100.16 & 100.00 & \\
\hline
\end{tabular}

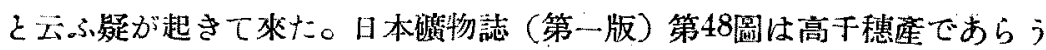
と思はるつに至つた。事實此等兩產地産のダンブッ石が從來唯單に尾平產 として一般に出く行渡つてるら椂である。

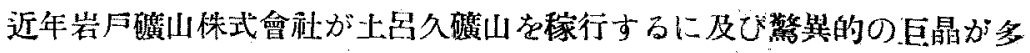
數に發兒せられた。然し其舀相は M. Weber 氏の記载されたものとは全然

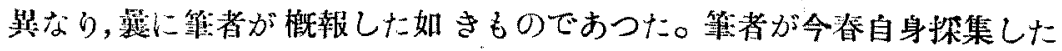
結晶の中には M. Weber 氏の記載せるものに眦似するものを獲たことは。

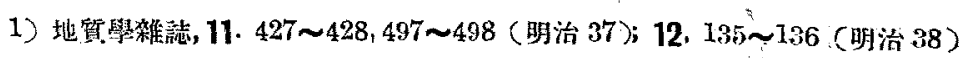


前述の如くである。此寽の詳綝は別の機會に袈る。

土邑久産ダン゙リ石の殆んど全てはその結晶の內部に白色乃至淡緣白色 の針狀結晶0)包裹物（解閃石類）学有す。分析筫料は此部分を避け無色透 明の部分を探取し，商工省地塤調查所長山根博士の御好意により，同所の手

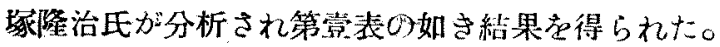

I は分析值，II は水分它去り 100 に計算せるものである。以上の結果よ り $\mathrm{SiO}_{22}: \mathrm{B}_{2} \mathrm{O}_{3}: \mathrm{CaO}=2.00: 1.02: 1.00=2: 1: 1$ となり,ダンブリ石の化學 式 $\mathrm{B}_{2} \mathrm{O}_{3} \cdot \mathrm{CaO} \cdot 2 \mathrm{SiO}_{2}$ 量く一致方后。

ダンブリ石の化學成分は其光學恒數と同じく殆んど一定であることは翼 きに筆者の述べた所である。この事實は文 G. M. Morey,及び Earlingerson 兩E ${ }^{2} O \mathrm{Na}_{2} \mathrm{O}-\mathrm{CaO}-\mathrm{B}_{2} \mathrm{O}_{3}-\mathrm{SiO}_{2} O$ 四成分系O研究に於て更らに明かに されてるる。

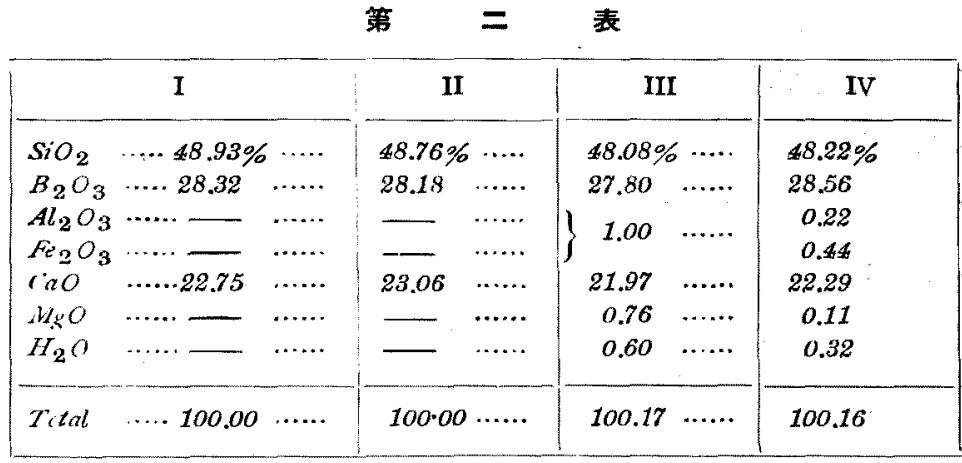

I ……ダンブリ不理論值, II……7 地 15 の分析值平均, III ……尾平 ダッブリ不分析值，IV ……上呂久座ダンブリ不分析值

1) Z.X. 79, 353 (1931).

2) Amer. Miaeral. 22.37 47 (1937).

3) Z. X. 79, 354,364 (1931) に此等 15 の分析值あり。

4) Z. X. 79,364 (1931). 
今ダンブリ石け理論値, 從爽發表さ礼てるるて產地 15 のダンブリ石の分 析值の本均及び尾本新ダンブリ石り分析随と本地のダンブリ石と在比較 すれば第二表となる。

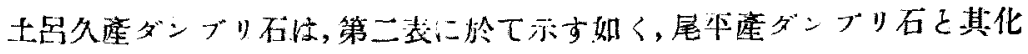

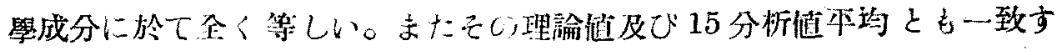
るを見る。

\section{2.邆安金山第洞產ルードウキタ石}

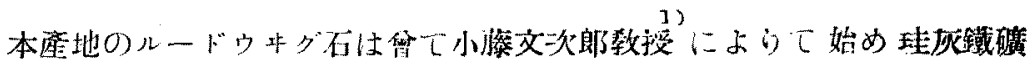

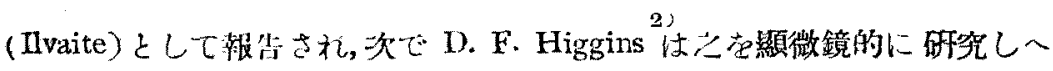
デンベルグ辉石型の非常に鐵に富む恽石で $(\mathrm{Ca}, \mathrm{Fe})\left(\mathrm{SiO}_{3}\right)_{2}$ 系O)鐵の端成

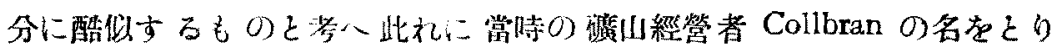
“Collbranite”を假に命名したのである。更に後に E. V. Shannon 氏 は同曂山より試料を得て之分析し正党のルードウェダ石に同定した。保 科正昭氏 茫此 Shannon 氏の分析に使用した試料は碃物學上の記載がない

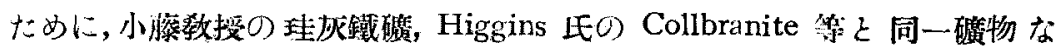

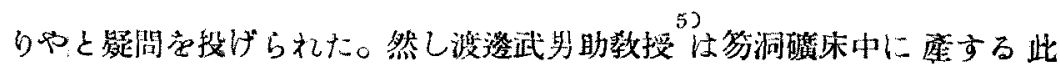
種の䃈物は唯一種のみでその性質は全く一漛であることから小蓃教授の記

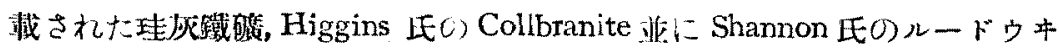

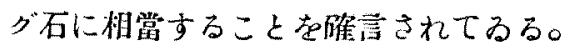

簕者が立に艆告せんとするルードウキグ石は派浚助教授自身が第洞に於 て探集せられたもの㕝同氏の御好意により惠與せられたものである。

1) 東大紀装, 27, 10-11 (明治43).

2) Econ. Geol. 13, 19 (1918).

3) Arner. Mineral. 6, 86 88 (1921); Proc. U.S. Nat. Mus. 59, 667 676(1321)

4) 地學雜誌, 33, 576 678 (大正 10).

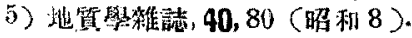




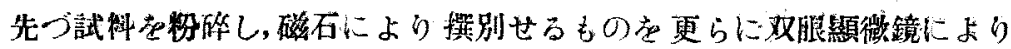
金く母岩末の附着せるもの除き之炃析に倛した。

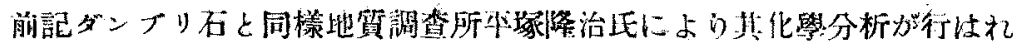
次の如き紹果が得られした。

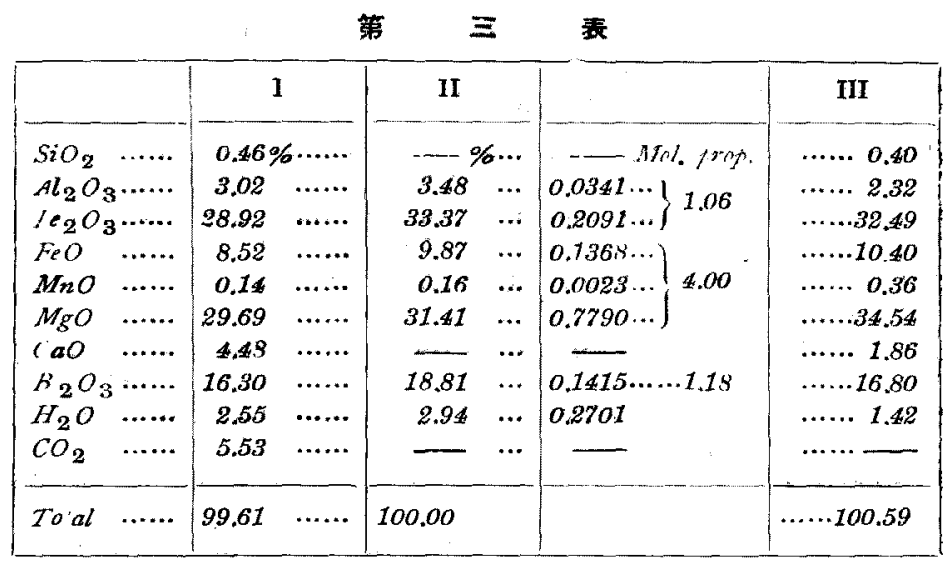

I は今回の分析值なるも $\mathrm{SiO}_{2}, \mathrm{CaO}, \mathrm{CO}_{2}$ O作柞は當試料中に少量の $\mathrm{Mg}_{2} \mathrm{SiO}_{4},(\mathrm{Mg}, \mathrm{Ca}) \mathrm{Co}_{3}$ が不純物として存すること范示すので此等成分

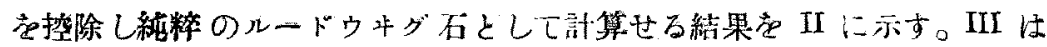
Shannon 氏 が第洞迹ルードウキダ石を分析して得られた絬果でおる。

II より $\mathrm{RO}: \mathrm{Fe}_{2} \mathrm{O}_{3}: \mathrm{B}_{2} \mathrm{O}_{3}$ O關倸を求むれば 4.00:1.06:I.I8 となり ルードウサグ石の化學式 $4 \mathrm{RO} \cdot \mathrm{Fe}_{2} \mathrm{O}_{3} \cdot \mathrm{B}_{2} \mathrm{O}_{3}$ 之一致する。

今回得た結果と Shannon 氏の分析直と农比較すると略は满足に一致す るのる見るが, 唯其 $\mathrm{H}_{2} \mathrm{O}$ の量に於て稍珙なる。

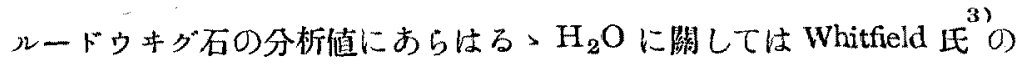

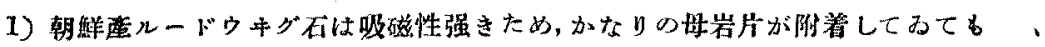
磁石に败引せらる。

2) Am. Journ. Sci., 34, 284 (1887)

3) Z. X. 48, 545 549 (1911); U. S. Geol. Sutv. Bull, 490, 29 32 (1911) 


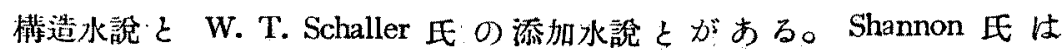

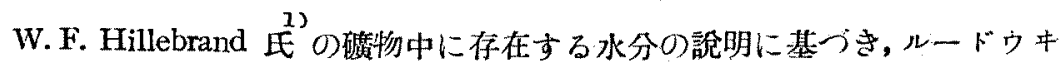
グ石が蟣维狀構造を有するために，その結晶の表面積が極めて大之なりて の結果多量の水分が吸着され，その吸着された水分が熔融默以上に於ても 存するものと解釋し, Schaller 氏の說を穻當とされてるる。

この観點から第洞座ルードキグ石に於て，今回の分析值を Shannon氏の 分析値との間に水分に多少の相異あることは, 分析試料の篟造の差哄に基 く吸着水の多少によるものとして說明し得る。殊に其主成分に於て兩者の

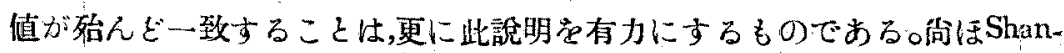
non 氏はルードゥキグ石殊に第洞库のものが强心磁性を呈することは, ル ードウキグ石中の二價の鐵が borate として存せず, ferrous ferrate として存

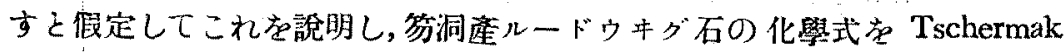
氏に從ひ, $3 \mathrm{MgO} \cdot \mathrm{B}_{2} \mathrm{O}_{3} \cdot(\mathrm{Fe}, \mathrm{Mg}) \mathrm{O} \cdot \mathrm{Fe}_{2} \mathrm{O}_{3}$ としてるる。即 ち $\mathrm{Mg}$ が $\mathrm{Fe}$ II $の$ 一部虹置換して, $(\mathrm{Fe}, \mathrm{Mg}) \mathrm{O} . \mathrm{Fe}_{2} \mathrm{O}_{3}$ の磁性分子の存在することを考へて るる。

この假定によつて本分析値 (第三表) 它處理すれば, 同㮏 $3 \mathrm{MgO} \cdot \mathrm{B}_{2} \mathrm{O}_{3}$ ・ $(\mathrm{Fe}, \mathrm{Mg}) \mathrm{O}, \mathrm{Fe}_{2} \mathrm{O}_{3}$ となり, $\mathrm{Mg}$ 多: $\mathrm{FeO} \mathrm{Fe}_{2} \mathrm{O}_{3}$ 分子の $\mathrm{Fe}^{l}$ の一部を置換した 磁性分子が存在し：そのために本分析試料も强き磁性足呈することが說明 出桃る。

1) U. S. Geol. Surv. Bull, 700, 64 63, (1919) 